\title{
A Facile Peroxo-Precursor Synthesis Method and Structure Evolution of Large Specific Surface Area Mesoporous $\mathrm{BaSnO}_{3}$
}

\author{
Chuande Huang, ${ }^{\dagger, \ddagger}$ Xiaodong Wang, ${ }^{* \dagger}$ Quan Shi, ${ }^{\dagger}{ }^{\dagger}$ Xin Liu, ${ }^{\dagger}$ Yan Zhang, ${ }^{\S}$ Fei Huang, ${ }^{\dagger, \ddagger}$ \\ and Tao Zhang \\ ${ }^{\dagger}$ Dalian Institute of Chemical Physics, Chinese Academy of Sciences, Dalian 116023, China \\ ${ }^{\ddagger}$ University of Chinese Academy of Sciences, Beijing 100049, China \\ ${ }^{\S}$ Qingdao Institute of Bioenergy and Bioprocess Technology, Chinese Academy of Sciences, Qingdao 266101, China
}

\section{Supporting Information}

\begin{abstract}
In this paper, we propose a facile and efficient strategy for synthesizing mesoporous $\mathrm{BaSnO}_{3}$ with a surface area as large as $67 \mathrm{~m}^{2} / \mathrm{g}$ using a peroxo-precursor decomposition procedure. As far as we know, this is the largest surface area reported in literature for $\mathrm{BaSnO}_{3}$ materials and may have a potential to greatly promote the technological applications of this kind of functional material in the area of chemical sensors, $\mathrm{NO}_{x}$ storage, and dyesensitized solar cells. The structure evolution of the mesoporous $\mathrm{BaSnO}_{3}$ from the precursor was followed using a series of techniques. Infrared analysis indicates large amount of protons and peroxo ligands are contained in the peroxo-precursor. Although the crystal structure of the precursor appears cubic according to the analysis of X-ray diffraction data, Raman and Mössbauer spectroscopy results show that the $\mathrm{Sn}$ atom is offset from the center of $\left[\mathrm{SnO}_{6}\right]$ octahedron. After calcination at different temperatures, the

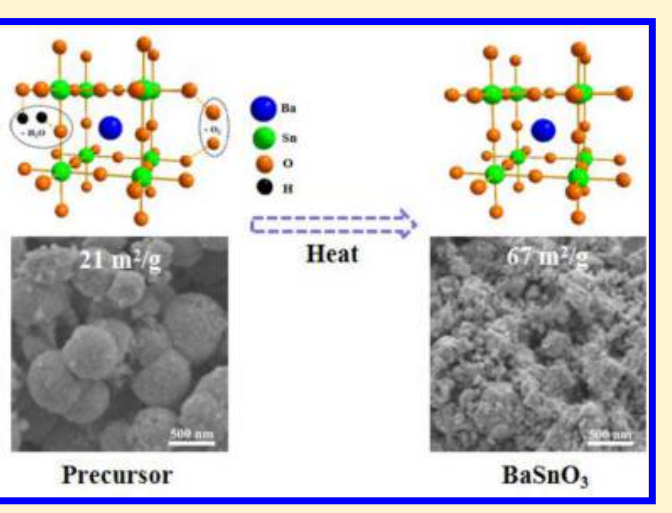
precursor gradually transforms into $\mathrm{BaSnO}_{3}$ by release of water and oxygen, and the distortion degree of $\left[\mathrm{SnO}_{6}\right]$ octahedral decreases. However, a number of oxygen vacancies are generated in the calcined samples, which are further confirmed by the physical property measurement system, and they would lower the local symmetry to some content. The concentration of the oxygen vacancies reduces simultaneously as the calcination temperature increases, and their contributions to the total heat capacity of the sample are calculated based on theoretical analysis of heat capacity data in the temperature region below $10 \mathrm{~K}$.
\end{abstract}

\section{INTRODUCTION}

$\mathrm{BaSnO}_{3}$ is an n-type semiconductor with a band gap of $3.1 \mathrm{eV}$ that has been widely studied by many researches due to its outstanding electric, photovoltaic, and optical nature. ${ }^{1-3}$ It has been found that $\mathrm{BaSnO}_{3}$ behaves with an ultrahigh sensitivity to a series of gases, such as $\mathrm{CO}, \mathrm{O}_{2}, \mathrm{H}_{2}, \mathrm{CH}_{4}, \mathrm{H}_{2} \mathrm{O}$, and ethanol, which may be applicable in the devleopment of innovative chemical gas and humidity sensors based on this kind of material. ${ }^{4-8}$ Besides, $\mathrm{BaSnO}_{3}$ is a potential material for reducing $\mathrm{NO}_{x}$ emission of diesel or lean-burn engines because of its fantastic $\mathrm{NO}_{x}$ sorption-desorption property. ${ }^{9,10}$ Studies by Kim et al. ${ }^{11}$ and Shin et al. ${ }^{12}$ showed that $\mathrm{BaSnO}_{3}$ exhibited fantastic performance when used as photoanode materials for dye-sensitized solar cells (DSSCs). La-doped $\mathrm{BaSnO}_{3}$ was reported to be a promising candidate for transparent conducting oxides (TCOs), and its electrical mobility could reach as large as $320 \mathrm{~cm}^{2} \mathrm{~V}^{-1} \mathrm{~s}^{-1}$, which is the largest value of all TCOs reported in literature. ${ }^{13-16}$

$\mathrm{BaSnO}_{3}$ crystals belongs to an ideal cubic perovskite structure (space group $\mathrm{Pm} 3 \mathrm{~m}$ ), in which $\mathrm{Ba}^{2+}$ ions locate at the center of the cell, while $\mathrm{Sn}^{4+}$ ions occupy the corner of the cube, and each $\mathrm{Sn}$ atom sixfold coordinated to oxygen sits at the center of the perfect octahedron. ${ }^{17}$ This local crystal structure is closely related to the physical properties of $\mathrm{BaSnO}_{3}$ stated above, and many researchers attempted to understand this particular feature in their work. For example, Liu et al. ${ }^{15}$ studied the origin of the superior conductivity of $\mathrm{BaSnO}_{3}$ in depth using the first-principle band structure calculations, and pointed out that the local structure distortion and strength of $\mathrm{Sn}-\mathrm{O}$ hybridization were two important factors that were likely to affect the materials' conductivity. Hadjarab et al. ${ }^{18}$ suggested that the oxygen deficiency in the $\mathrm{BaSnO}_{3}$ structure could play a crucial role in achieving a high conductivity in the material.

Another technically important aspect involved in this research field is the surface area investigations of $\mathrm{BaSnO}_{3^{-}}$ based materials since it may be applicable for fabricating highperformance chemical gas or humidity sensors, $\mathrm{NO}_{x}$ storage medium, and DSSCs. $\mathrm{Li}$ et al. ${ }^{19}$ found that $\mathrm{SnO}_{2}$ with higher surface area was more sensitive to $\mathrm{H}_{2}$ gas. Studies by Xu et al. ${ }^{20}$ showed that the sensitivity of $\mathrm{SnO}_{2}$ to $\mathrm{CO}$ was significantly enhanced by increasing the surface-to-volume ratio of $\mathrm{SnO}_{2}$.

Received: February 4, 2015

Published: April 3, 2015 
Tao et al. ${ }^{21}$ pointed out that gas-sensoring property of $\mathrm{BaSnO}_{3}$ was surface-reaction controlled. In addition, preparation of crystalline $\mathrm{BaSnO}_{3}$ with high surface area is important to improve the dye loading on DSSC photoanodes. ${ }^{11}$ Guo et al. ${ }^{22}$ showed that the performance of cell with dye-sensitized $\mathrm{BaSnO}_{3}$ electrodes was dramatically elevated by increasing the dye loading from $1.08 \times 10^{-7}$ to $2.17 \times 10^{-7} \mathrm{~mol} \cdot \mathrm{cm}^{-2}$. It turns out that the key step of making the $\mathrm{BaSnO}_{3}$ materials applicable in these areas is to explore a way of obtaining larger specific surface areas in the material, and a number of researchers have proposed various $\mathrm{BaSnO}_{3}$ synthesis techniques for this purpose.

The conventional $\mathrm{BaSnO}_{3}$ synthesis procedure is to sinter the corresponding mixed starting materials at temperatures of ca. $1200{ }^{\circ} \mathrm{C}$ through a solid-state reaction. However, this method normally leads to polycrystalline $\mathrm{BaSnO}_{3}$ with serious agglomerations and consequently low surface areas. ${ }^{23,24}$ To lower the crystallization temperature and suppress grain growth, many approaches have been reported, including hydrothermal synthesis, microemulsion method, alkoxide hydrolysis synthesis, sol-gel method, peroxide route, and so on. ${ }^{25-31}$ Most of these methods are focusing on improving the surface area of $\mathrm{BaSnO}_{3}$ by decreasing the particle size in the preparation. However, it does not seem to be efficient. For example, $\mathrm{BaSnO}_{3}$ (ca. $40 \mathrm{~nm}$ ) prepared by sol-gel method and calcined at $750{ }^{\circ} \mathrm{C}$ for $4 \mathrm{~h}$ showed a surface area of only $14 \mathrm{~m}^{2} /$ g. ${ }^{10}$ The surface area of $\mathrm{BaSnO}_{3}(30-60 \mathrm{~nm})$ obtained by hydrothermal preparation at $260{ }^{\circ} \mathrm{C}$ was only $5.3 \mathrm{~m}^{2} / \mathrm{g} \cdot{ }^{30} \mathrm{~A}$ surface area of ca. $25 \mathrm{~m}^{2} / \mathrm{g}$ was achieved for $\mathrm{BaSnO}_{3}(30 \mathrm{~nm})$ synthesized via a wet chemical peroxide route and calcined at $800{ }^{\circ} \mathrm{C}$, but its preparation condition was rigorous $\left(10{ }^{\circ} \mathrm{C}\right.$ under argon protection), and the pure $\mathrm{BaSnO}_{3}$ appeared at a relatively high temperature of $900{ }^{\circ} \mathrm{C} .{ }^{31}$ Besides decreasing the particle size, fabrication of porous structures is also proposed to be effective in increasing the surface area. ${ }^{32,33} \mathrm{Li}$ et al. ${ }^{34}$ prepared one-dimensional porous $\mathrm{BaSnO}_{3}$ hollow architectures by releasing $\mathrm{CO}_{2}$ from solid-state reaction between $\mathrm{BaCO}_{3}$ core and $\mathrm{SnO}_{2}$ shell, and a surface area of ca. $13 \mathrm{~m}^{2} / \mathrm{g}$ was obtained. Buscaglia et al. ${ }^{35}$ have synthesized porous $\mathrm{BaSnO}_{3}$ with a specific surface area of $30-40 \mathrm{~m}^{2} / \mathrm{g}$ by heating the $\mathrm{BaSn}(\mathrm{OH})_{6}$ precursor (ca. $2 \mathrm{~m}^{2} / \mathrm{g}$ ) at $400{ }^{\circ} \mathrm{C}$. It is worth noting that most of these works are related to high surface area achievement, but few focus on understanding the structure evolution of $\mathrm{BaSnO}_{3}$ during the synthesis procedure. Köferstein et al. ${ }^{36}$ reported that an unknown barium tin oxycarbonate intermediate phase $\left(\mathrm{BaSnO}\left(\mathrm{CO}_{3}\right)_{2}\right)$ was formed in the phase evolution of the $\left[\mathrm{Ba}\left(\mathrm{C}_{2} \mathrm{H}_{6} \mathrm{O}_{2}\right)_{4}\right]\left[\mathrm{Sn}\left(\mathrm{C}_{2} \mathrm{H}_{4} \mathrm{O}_{2}\right)_{3}\right]$ precursor to $\mathrm{BaSnO}_{3}$.

In this work, we present a facile method of synthesizing mesoporous $\mathrm{BaSnO}_{3}$ with large specific surface areas by the decomposition of a peroxo-precursor, which is prepared through reacting barium carbonate with stannate in basic hydrogen peroxide solution. The as-prepared $\mathrm{BaSnO}_{3}$ obtained by calcination of the peroxo-precursor at $500{ }^{\circ} \mathrm{C}$ shows a specific surface area as large as $60-70 \mathrm{~m}^{2} / \mathrm{g}$, which is the largest value reported in literature for $\mathrm{BaSnO}_{3}$ as far as we know. The structure evolution from the precursor to final $\mathrm{BaSnO}_{3}$ products is systematically investigated using X-ray diffraction (XRD), scanning electron microscopy (SEM), thermogravimetry (TG), differential thermal analysis (DTA), mass-spectra (MS) with temperature-programmed desorption (TPD), infrared (IR) analysis, Raman spectroscopy, and ${ }^{119} \mathrm{Sn}$ Mössbauer spectroscopy. In addition, the $\mathrm{BaSnO}_{3}$ samples prepared from sintering the precursor above $400{ }^{\circ} \mathrm{C}$ were measured using a physical property measurement (PPMS) system in the temperature range from 1.9 to $300 \mathrm{~K}$, and the results indicate a significant linear heat capacity contribution of the oxygen vacancies existing in the materials. The enthalpies of these samples at $298.15 \mathrm{~K}$ are also calculated based on the curve fitting of the experimental heat capacity data.

\section{EXPERIMENTAL SECTION}

2.1. Material Preparation. All reagents in the preparation procedure were of analytical reagent grade and used without further purification. The starting solution was prepared by dissolving $\mathrm{SnCl}_{4}$. $5 \mathrm{H}_{2} \mathrm{O}$ (2 mmol; 99\%, Kermel, Tianjin, China) in a transparent $\mathrm{H}_{2} \mathrm{O}_{2}$ aqueous solution $(40 \mathrm{~mL}$; $30 \%$, Kermel, Tianjin, China) with a $\mathrm{pH}$ value $\sim 9$, which was adjusted by dropwise addition of ammonia solution (25\%, Kermel, Tianjin, China) into the solution with magnetic stirring. Subsequently, $\mathrm{BaCO}_{3}$ powders $\left(2 \mathrm{mmol} ; S_{\mathrm{BET}}=\right.$ $1.8 \mathrm{~m}^{2} / \mathrm{g} ; 99 \%$, Kermel, Tianjin, China) were introduced to the solution at room temperature, forming a suspension that was then heated to $95{ }^{\circ} \mathrm{C}$ and kept for $5 \mathrm{~h}$ in a water bath. A white precipitate was generated during this process. The precipitate was filtered from the solution and then washed with deionized water until the $\mathrm{pH}$ of filtrate was $\sim 7$, and a peroxo-precursor was then obtained by drying the precipitate overnight in an oven at $120^{\circ} \mathrm{C}$ (marked as BS-120). The peroxo-precursor was calcined in static air at 200, 300, 400, 500, 600 , and $800{ }^{\circ} \mathrm{C}$ for $4 \mathrm{~h}$, respectively, and finally the $\mathrm{BaSnO}_{3}$ products were obtained and denoted as BS-T ( $\mathrm{T}$ represents the calcination temperature). For comparison, $\mathrm{SnO}_{2}$ precursor was prepared in the absence of $\mathrm{BaCO}_{3}$ undergoing the same procedure (precipitated at 95 ${ }^{\circ} \mathrm{C}$, filtered, washed and dried at $120^{\circ} \mathrm{C}$ ), and marked as S- 120 .

2.2. Characterization. The phase composition was examined at room temperature using a PANalytical $\mathrm{X}^{\prime}$ Pert-Pro powder X-ray diffractometer with $\mathrm{Cu} \mathrm{K} \alpha$ radiation $(\lambda=0.1541 \mathrm{~nm})$. IR analysis was performed over the range of $400-4000 \mathrm{~cm}^{-1}$ on a Fourier transform infrared (FT-IR) spectrometer (Bruker Equinox 55) in the form of $\mathrm{KBr}$ discs. TG and DTA were performed on TA Q600 equipment in dry air atmosphere with a constant heating rate of $10{ }^{\circ} \mathrm{C} / \mathrm{min}$. An independent MS (OMNISRAR) analysis with $\mathrm{He}$ as carrier gas was used to monitor the gases released during the TPD experiment (constant heating rate of $10{ }^{\circ} \mathrm{C} / \mathrm{min}$ ). $\mathrm{N}_{2}$ adsorption-desorption analysis was performed on a Quadrasorb SI instrument. Before the measurements, the BS-120, BS-200, and BS-300 samples were degassed in vacuum for $5 \mathrm{~h}$ at 100,150 , and $250^{\circ} \mathrm{C}$, respectively. The other samples (BS-400, BS-500, BS-600, and BS-800) were degassed at $300{ }^{\circ} \mathrm{C}$ in vacuum for $5 \mathrm{~h}$. The specific surface area was calculated using a Brunauer-Emmett-Teller (BET) method over the range of $P / P_{0}$ from 0.05 to $0.30 .^{37,38}$ The Barrett-Joyner-Halenda $(\mathrm{BJH})$ pore size distribution curves were obtained according to the adsorption branches of the isotherms. The morphologies of all samples were investigated using field-emission SEM (JEOL JSM-7800F). The Raman spectroscopy was recorded using a Jobin LabRAM HR 800 spectrophotometer equipped with an Ar laser $(532 \mathrm{~nm})$. The roomtemperature Mössbauer spectra were recorded using ${ }^{119} \mathrm{Sn}$ as the radiation source $\left(\mathrm{BaSnO}_{3}\right.$ matrix), and the isomer shifts were shown with respect to $\mathrm{BaSnO}_{3}$ at room temperature.

The crystallite sizes of the calcined samples were calculated using Scherer formula without the consideration of strain: ${ }^{39} D=0.9 \lambda / B$ cos $\theta$, where $\theta$ is the diffraction angle, $B$ indicates the full width at halfmaximum, and $\lambda$ is the wavelength of the incident $X$-rays $(0.1541 \mathrm{~nm})$.

The heat capacities of BS-400, BS-500, BS-600, and BS- 800 samples were measured using a Quantum Design PPMS in zero magnetic field with logarithmic spacing from 1.9 to $100 \mathrm{~K}$ and in $10 \mathrm{~K}$ intervals from 100 to $300 \mathrm{~K}$. The heat capacity measurement accuracy was verified by measuring a high-purity copper pellet and found to be $\pm 2 \%$ below 20 $\mathrm{K}$ and within $\pm 1 \%$ from 20 to $400 \mathrm{~K}$. The powdered sample was measured using a technique developed by Shi et al., ${ }^{40,41}$ which can achieve an accuracy of $\pm 2 \%$ below $10 \mathrm{~K}$ and $\pm 1 \%$ from 10 to $300 \mathrm{~K}$. The detailed sample preparation and calorimetric procedure can be found in refs 36 and 37. The sample mass used in the measurement is 

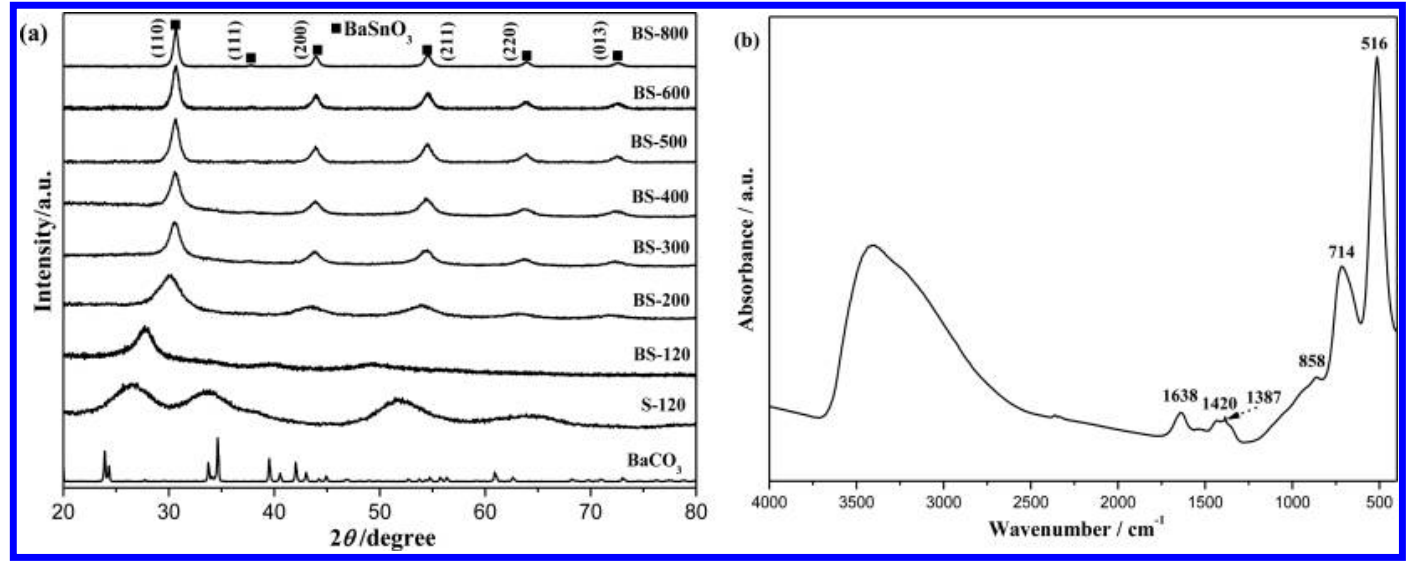

Figure 1. (a) XRD patterns of $\mathrm{BaCO}_{3}$ starting powder, S-120, and BS-T, and (b) FT-IR spectrum of BS-120.
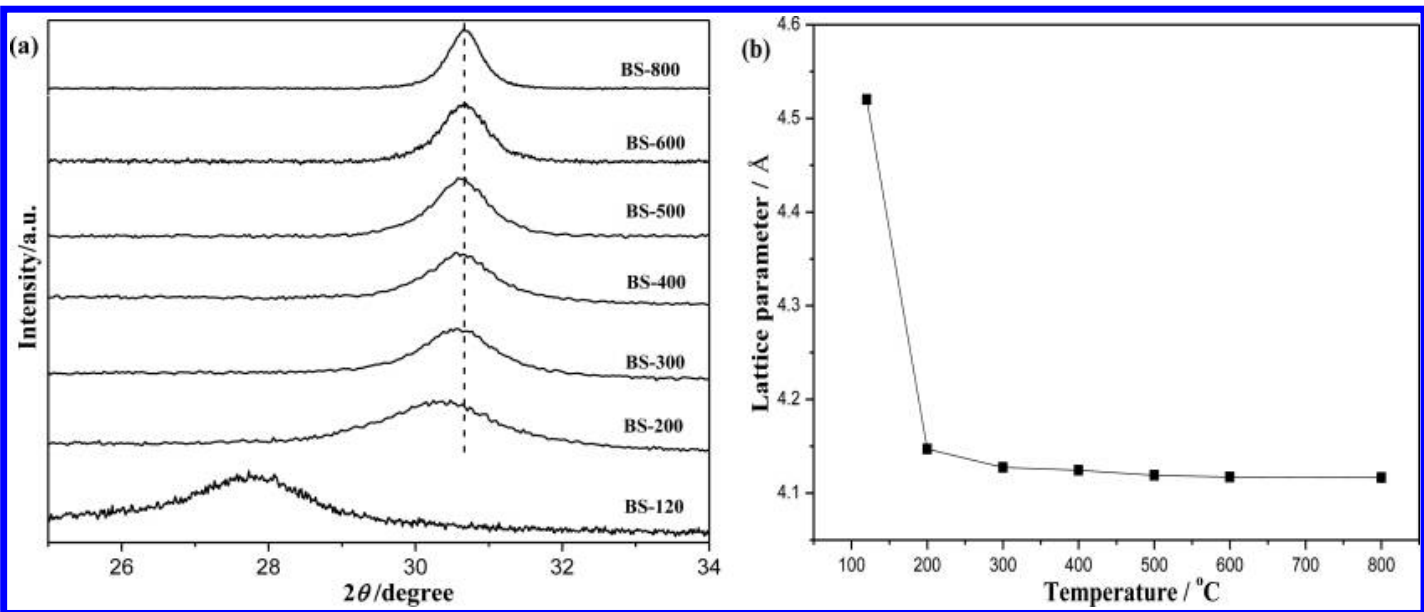

Figure 2. (a) Magnified XRD patterns of BS-T at $25^{\circ} \leq 2 \theta \leq 34^{\circ}$, and (b) lattice parameter calculated for BS-T samples.

$18.03,22.07,24.90$, and $23.32 \mathrm{mg}$ for BS-400, BS-500, BS-600, and BS800 , respectively.

\section{RESULTS AND DISCUSSION}

XRD patterns of the precursor of $\mathrm{BS}-120$, the $\mathrm{SnO}_{2}$ precursor of S-120, and the $\mathrm{BaCO}_{3}$ starting material are shown in Figure 1a. It can be seen that BS-120 exhibits a uniform phase without any observable traces of $\mathrm{BaCO}_{3}$ and $\mathrm{SnO}_{2}$. The structure details of BS-120 are further investigated by FT-IR spectra in Figure $1 \mathrm{~b}$. It can be seen that a broad band appearing from 2500 to $3700 \mathrm{~cm}^{-1}$ could be attributed to $\mathrm{O}-\mathrm{H}$ stretching mode from water and $\mathrm{SnO}-\mathrm{H}$ groups, while the peak located at $1638 \mathrm{~cm}^{-1}$ may be ascribed to the contribution of $\delta(\mathrm{H}-\mathrm{O}-\mathrm{H})$ vibration. ${ }^{42,43}$ A broad envelope at $1420 \mathrm{~cm}^{-1}$ and a shoulder at $858 \mathrm{~cm}^{-1}$, which are assigned to $\delta(\mathrm{O}-\mathrm{O}-\mathrm{H})$ and $\nu(\mathrm{O}-\mathrm{O})$ vibrations, respectively, could be observed, indicating the presence of peroxo ligands in the precursor. ${ }^{43}$ The peaks at 516 and $714 \mathrm{~cm}^{-1}$ can be ascribed to vibrations of $\mathrm{Sn}-\mathrm{OH}$ and $\mathrm{Sn}-\mathrm{O}-\mathrm{Sn}$ in the precursor, respectively. ${ }^{29,42}$ Besides, a weak and sharp band existing at $1387 \mathrm{~cm}^{-1}$ in the spectra resulting from $\nu(\mathrm{C}-\mathrm{O})$ vibrations can be observed from the FT-IR spectra, suggesting that some carbonate impurities might be included in BS-120. ${ }^{43}$ However, these impurity contents are relatively small, could not be detected in the XRD patterns, and therefore can be ignored in the following $\mathrm{BaSnO}_{3}$ synthesis from the peroxo-precursor.

The XRD pattern evolution of the $\mathrm{BaSnO}_{3}$ obtained by calcination of the peroxo-precursor at different temperatures is also included in Figure 1a. As can be seen from the figure, all BS-T samples reveal a single phase with cubic perovskite lattice. Besides, the prominent reflection peak of BS-120 around $27.8^{\circ}$ shifts to the higher $2 \theta$ positions in the $\mathrm{BaSnO}_{3}$ samples, which is illustrated more clearly by the magnified view $\left(25^{\circ} \leq 2 \theta \leq\right.$ $34^{\circ}$ ) in Figure 2a. Such a shift is likely due to the lattice parameters decreasing gradually during the $\mathrm{BaSnO}_{3}$ formation process with the calcination temperature increasing. For BS-T samples calcined at above $400{ }^{\circ} \mathrm{C}$, all of the diffraction peaks could be well-indexed to the standard patterns of the cubic $\mathrm{BaSnO}_{3}$ phase [JCPDS 89-2488], suggesting that these samples have transferred to a $\mathrm{BaSnO}_{3}$ phase. Also, the crystallite sizes were estimated to be $8.9,10.7,12.7$, and 17.9 $\mathrm{nm}$ for BS-400, BS-500, BS-600, and BS-800, respectively, based on the full width half maxima of the prominent (110) reflection in the XRD patterns using the Scherer's equation. To further detect the lattice evolution during the calcination process, the lattice constant $a$ of all BS-T samples were calculated, and the results are presented in Figure 2b. Note that the most significant decline of lattice parameter is observed between BS-120 and BS-200 (from 4.520 to $4.147 \AA$ ), and then the value of the unit cell edge decreases slowly with the increase of calcination temperatures. After calcined above $500{ }^{\circ} \mathrm{C}$, the lattice constant $a$ of BS-T samples can be maintained at $\sim 4.119$ $\AA$, which coincides with the reported value of $4.118 \AA$ in literature for $\mathrm{BaSnO}_{3}{ }^{44}$

To probe the structure evolution of BS-T samples during the calcination process, the decomposition feature of BT-120 was 
monitored using the TG-DTA and MS techniques. The total weight loss values of BS-T samples from the TG analysis are summarized in Table 1. Combining both measurement results,

Table 1. Total Weight Loss, Surface Area, Pore Volume and C Constant of BS-T Samples

\begin{tabular}{lcccc} 
samples & $\begin{array}{c}\text { weight loss } \\
(\%)\end{array}$ & $\begin{array}{c}\text { surface area } \\
\left(\mathrm{m}^{2} / \mathrm{g}\right)\end{array}$ & $\begin{array}{c}\text { pore volume } \\
\left(\mathrm{cm}^{3} / \mathrm{g}\right)\end{array}$ & $\begin{array}{c}C \\
\text { constant }\end{array}$ \\
BS-120 & 12.3 & 21.2 & 0.055 & 107 \\
BS-200 & 8.5 & 20.1 & 0.076 & 96 \\
BS-300 & 5.4 & 14.0 & 0.069 & 146 \\
BS-400 & 2.9 & 40.1 & 0.081 & 80 \\
BS-500 & 1.9 & 67.2 & 0.087 & 56 \\
BS-600 & 1.1 & 36.9 & 0.079 & 84 \\
BS-800 & 0.1 & 28.0 & 0.081 & 99 \\
\hline
\end{tabular}

as shown in Figure 3, the decomposition process of BS-120 precursor can be divided into three distinct steps as the temperature increases from room temperature to $800{ }^{\circ} \mathrm{C}$. The first step is below $150{ }^{\circ} \mathrm{C}$ where a small weight loss $(\sim 1 \%)$ appears in TG-DSC and only water content is observed in MS, indicating that a small amount of weakly bonded water or hydroxyl groups are evaporated from BT-120. The second step can be identified in the temperature range from 150 to $400{ }^{\circ} \mathrm{C}$. In this step, a significant amount of weight loss of ca. $9 \%$ and relatively large water and oxygen signals are found in TG-DSC and MS curves, respectively, suggesting that a large number of water and oxygen are rapidly released in this temperature region. Additionally, two exothermal peaks can be noticed in the heat flow curve as shown in Figure 3a, which is likely due to the decomposition process of peroxo groups into oxygen. However, it is clearly shown that this process could be finished mainly below $400{ }^{\circ} \mathrm{C}$ since no more oxygen signal can be found at higher temperatures in the MS curve.

As for the last step above $400{ }^{\circ} \mathrm{C}$, only a small amount of water loss $(2 \%)$ can be detected, which is likely attributed to the strongly bonded hydroxyl groups released from the precursor at high temperatures. It is suggested that, compared to the peroxo groups, the strongly bonded hydroxyl groups are relatively difficult to be removed from the precursor during the calcinations process. In addition, a trace of $\mathrm{CO}_{2}$, which could result from the decomposition of the carbonate impurities from the precursor, can be noticed in the MS curve in this step. On the basis of the fact of this BS-120 decomposition process, it is reasonable to conclude that the large lattice constant of BS-120 mentioned in the above XRD results is likely due to a multitude of hydroxyl and peroxo ligands incorporated in the sample, and the significant decline of lattice constant of BT-120 to those of $\mathrm{BaSnO}_{3}$ samples may be on account of a significant amount of hydroxyl and peroxo ligands removed from the precursor in the second step.

The BET surface areas of all BS-T samples obtained using the $\mathrm{N}_{2}$ adsorption at the temperature of $-196{ }^{\circ} \mathrm{C}$ are listed in Table 1 . It can be seen that the surface area slowly decreases from BT-120 to BT-300, increases greatly from BT-300 to BT500 , reaches the largest value of $67.2 \mathrm{~m}^{2} / \mathrm{g}$, and then decreases again from BT-500 to BT-800. Such a surface area evolution could be understood from a competition between the particle growth and the mesoporous structure formation due to the water and oxygen removal during the calcination process. At low temperatures, only the small amount of weakly bonded water or hydroxyl groups are removed, with most of the hydroxyl and peroxo ligands remaining in the sample, and consequently the surface area does not change significantly. However, as the temperature continues increasing to $500{ }^{\circ} \mathrm{C}$, a large number of water and oxygen is released, and a mesoporous structure formation could be expected in the samples, which can be confirmed in the following nitrogen adsorption-desorption isotherm and SEM determination. Although the particle size would grow with increasing calcination temperature, the mesoporous structure formation is predominant during this process. As the sample calcined at higher temperatures, the particles prefer to aggregate together with the mesoporous structure gradually disappearing, and therefore the surface area tends to decrease. It is worth mentioning that the surface area of $67.2 \mathrm{~m}^{2} / \mathrm{g}$ achieved in BT500 is the largest value reported in literature, as far as we know, and also can be maintained a relatively large value of $\sim 30 \mathrm{~m}^{2} / \mathrm{g}$ even at the higher calcination temperature of $800{ }^{\circ} \mathrm{C}$. It suggests that the peroxo-precursor decomposition method is a efficient way to synthesize $\mathrm{BaSnO}_{3}$ materials with large surface areas.

To further explore the mesoporous structure of the $\mathrm{BaSnO}_{3}$ samples, the nitrogen adsorption-desorption isotherms and the $\mathrm{BJH}$ pore size distribution curves of BS-T samples calcined from 400 to $800{ }^{\circ} \mathrm{C}$ are collected in Figure 4 (and Supporting Information, Figure S1). As can be seen in Figure 4a, all of these samples exhibit a type IV isotherm with a hysteresis loop, confirming that the mesoporous structure is formed in the samples. Taking the sample's decomposition process into account, the formation of the mesopores is mostly ascribed to

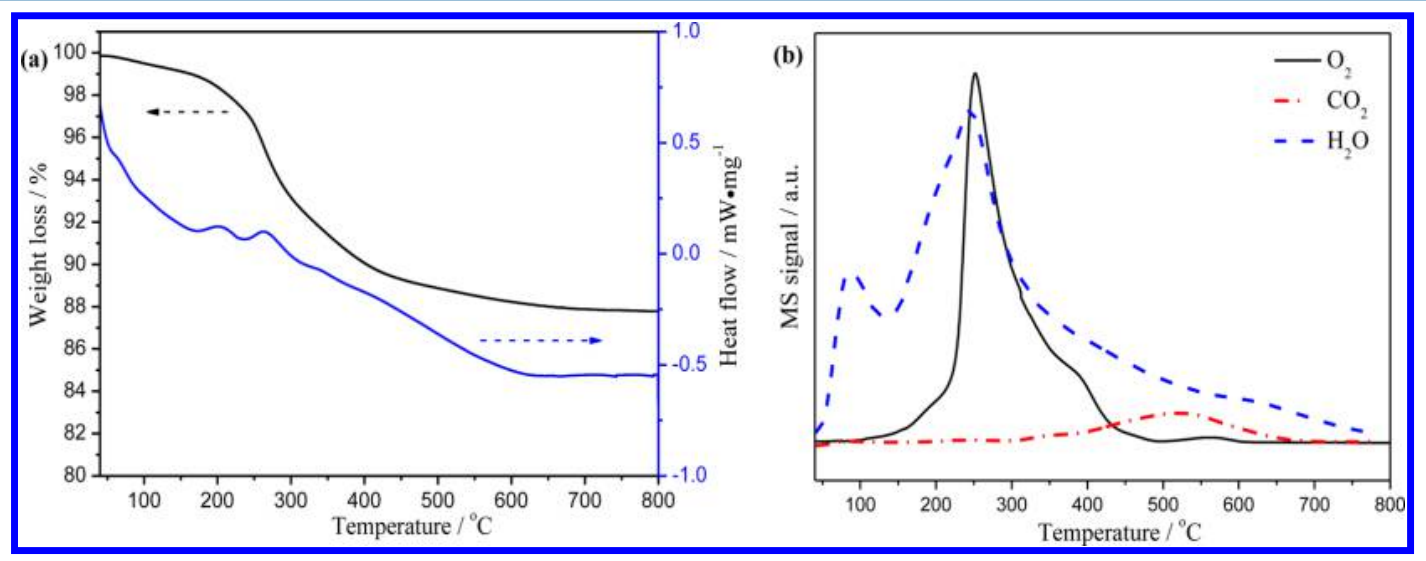

Figure 3. (a) TG-DTA curve for BS-120; (b) MS signals of the released gas during the heat-treatment of BS-120. 

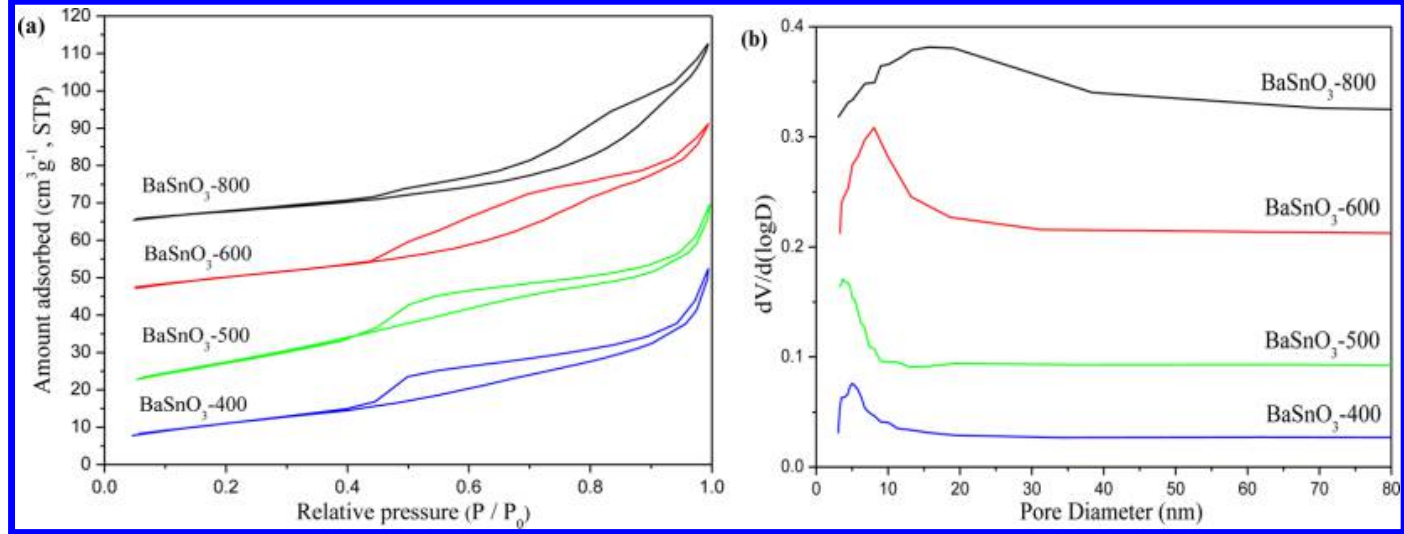

Figure 4. (a) $\mathrm{N}_{2}$ physisorption isotherms and (b) pore size distribution plots (calculated from the adsorption branch) of BS-400, BS-500, BS-600, and BS-800. The $\mathrm{N}_{2}$ sorption isotherms of BS-800, BS-600, and BS-500 are offset vertically by 60,40 , and $10 \mathrm{~cm}^{3} \mathrm{~g}^{-1}$, respectively.
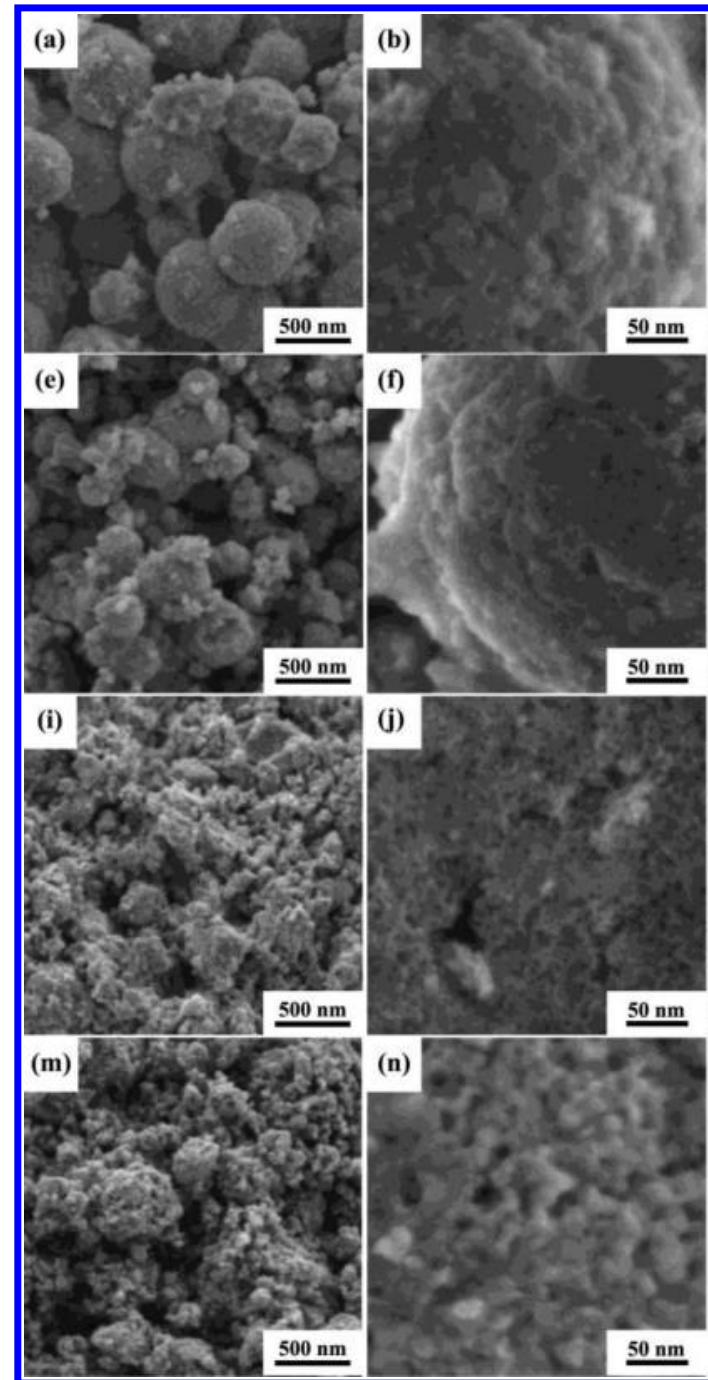

(n)
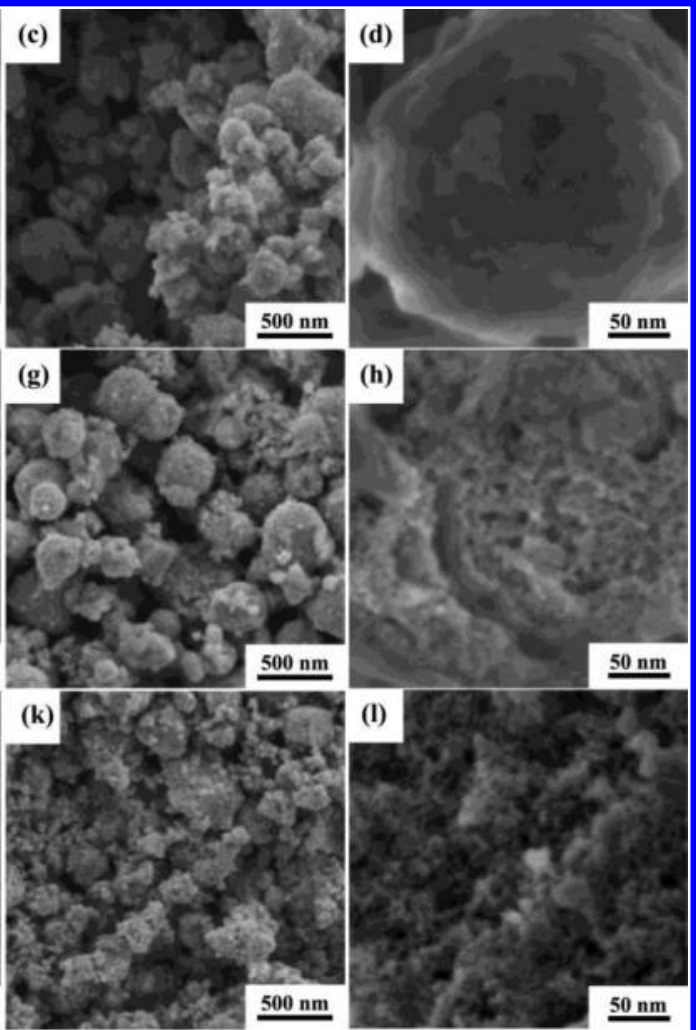

Figure 5. SEM images of (a, b) BS-120, (c, d) BS-200, (e, f) BS-300, (g, h) BS-400, (i, j) BS-500, (k, l) BS-600, and (m, n) BS-800.

release of water and oxygen from the precursor. The hysteresis loops vary from sample to sample indicating the differences in pore-size distribution (Figure 4b). For BS-400 and BS-500 samples, there is a sharp peak in the range from 3.5 to $8.0 \mathrm{~nm}$, indicating that their pore size distributions are mainly concentrated in this region. However, in the case of BS-600 and BS-800, the pore size distribution is gradually widened as the calcination temperature increases, revealing the $\mathrm{BaSnO}_{3}$ particle growth during the calcination process.

The morphology of the BS-T samples calcined at different temperatures characterized by SEM is shown in Figure 5 . Clearly, BS-120 (Figure 5a) mainly consists of spherical particles with sizes varying from 100 to a few hundred nanometers, and no noticeable pores can be detected on the 
surface (Figure 5b). This spherical morphology does not change much until calcining the sample at 200 and $300{ }^{\circ} \mathrm{C}$ (Figure $5 c-f)$. However, some mesopores could be observed on the surface of BS-400 (Figure 5h), which is likely to account for the surface area increasing at higher calcination temperatures. For the BT-500 sample (Figure 5i), the spherical structure of the precursor tends to collapse under the high internal pressure generated by the water and oxygen release, and consequently a number of nanoparticles with mesoporous structures can be obtained. As calcination temperatures increase to 600 and $800{ }^{\circ} \mathrm{C}$ (Figure $5 \mathrm{k}-\mathrm{n}$ ), the growth of $\mathrm{BaSnO}_{3}$ particles is notable, and the pore size increases simultaneously. These observations are well-consistent with the $\mathrm{N}_{2}$ adsorptiondesorption results discussed above.

The structure evolution of the BS-120 precursor to the BS-T samples is investigated by ${ }^{119} \mathrm{Sn}$ Mössbauer spectra, from which the chemical state of $\mathrm{Sn}$ on a atomic scale can be detected with a high sensitivity based on the obtained values of isomer shift (IS) and quadrupole splitting (QS). ${ }^{45}$ The IS value is closely related to the valence state and atomic spacing, while the QS value is sensitive to the symmetry of the charge around the Sn atom. ${ }^{46}$ The experimental and fitted Mössbauer spectra data for BS-T and S-120 at room temperature are shown in Figure 6,

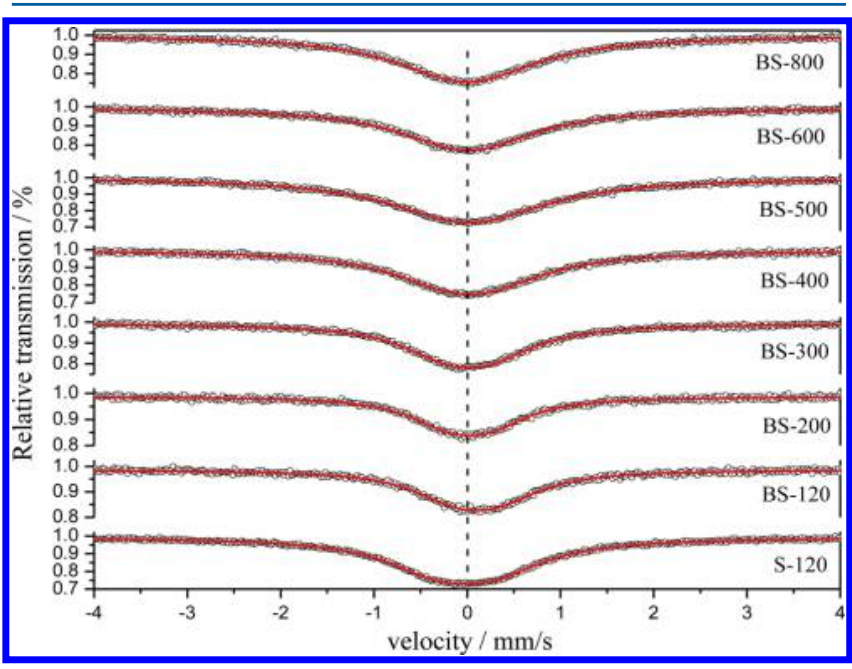

Figure 6. Room-temperature ${ }^{119} \mathrm{Sn}$ Mössbauer spectra of S-120 (bottom) and BS-T samples.

and the corresponding parameters are given in Table 2. The IS values of $\mathrm{Sn}^{4+}$ and $\mathrm{Sn}^{2+}$ are generally located in the range of $(-0.4$ to 2.0$) \mathrm{mm} / \mathrm{s}$ and $(2.3$ to 4.5$) \mathrm{mm} / \mathrm{s}$ (relative to

Table 2. Room-Temperature ${ }^{119}$ Sn Mössbauer Parameters

\begin{tabular}{|c|c|c|c|}
\hline samples & $\mathrm{IS}^{a}(\mathrm{~mm} / \mathrm{s})$ & $\mathrm{QS}^{b}(\mathrm{~mm} / \mathrm{s})$ & $\mathrm{LW}^{c}(\mathrm{~mm} / \mathrm{s})$ \\
\hline S-120 & -0.01 & 0.62 & 1.36 \\
\hline BS-120 & 0.07 & 0.51 & 1.40 \\
\hline BS-200 & 0.02 & 0.47 & 1.04 \\
\hline BS-300 & 0.02 & 0.44 & 1.22 \\
\hline BS-400 & 0.02 & 0.39 & 1.64 \\
\hline BS-500 & 0.02 & 0.30 & 1.99 \\
\hline BS-600 & 0.01 & 0.00 & 1.74 \\
\hline BS- 800 & 0.00 & 0.00 & 1.78 \\
\hline Bulk $\mathrm{BaSnO}_{3}{ }^{d}$ & 0.00 & 0.00 & \\
\hline
\end{tabular}

${ }^{a}$ Isomer shift relative to $\mathrm{BaSnO}_{3} .{ }^{b}$ Quadrupole splitting. ${ }^{c}$ Line width. ${ }^{d}$ Data taken from ref 14
$\mathrm{BaSnO}_{3}$ ), respectively. ${ }^{14}$ As for the IS values listed in Table 2, all of them are located in the $(-0.4$ to 2.0$) \mathrm{mm} / \mathrm{s}$ region, indicating that the $\mathrm{Sn}$ atom in the BS-T and S-120 samples are exclusively in +4 oxidation state. Also, the IS values of BS-T samples tend to slightly decrease with increasing calcination temperature, revealing a decrease of the $S$ electron density in the $\mathrm{Sn}$ atom. In other words, the $\mathrm{Sn}-\mathrm{O}$ interaction in the BS-T samples presents as strengthened as the calcination process goes to higher temperatures.

As for the quadrupole splitting feature listed in Table 2, the $\mathrm{QS}$ values for BS-T $(120 \leq \mathrm{T} \leq 400)$ samples are much larger than that of bulk $\mathrm{BaSnO}_{3}(0 \mathrm{~mm} / \mathrm{s}),{ }^{14}$ suggesting that $\left[\mathrm{SnO}_{6}\right]$ octahedron is highly distorted because of the significant amount of the hydroxyl and peroxo groups included in the samples. And also, the slow reduction in the QS values with the temperature increase indicates that the symmetry of $\left[\mathrm{SnO}_{6}\right]$ octahedron is gradually improved with the water and oxygen removed from the sample.

According to the decomposition process discussed above, the hydroxyl groups and peroxo ligands are mostly removed after calcination at $500{ }^{\circ} \mathrm{C}$. However, BS-500 still shows a low local symmetry since its QS value is found to be as high as $0.30 \mathrm{~mm} /$ s. This may be caused by oxygen vacancies that could be generated by the hydroxyl groups releasing during the calcination, and the corresponding reaction can be presented below: ${ }^{47}$

$$
2 \mathrm{OH}^{\bullet}{ }_{\mathrm{O}} \rightarrow \mathrm{O}^{\bullet \bullet}{ }_{\mathrm{O}}+\mathrm{V}^{\bullet \bullet}{ }_{\mathrm{O}}+\mathrm{H}_{2} \mathrm{O}(\mathrm{g})
$$

Further calcination at 600 and $800{ }^{\circ} \mathrm{C}$ leads to reduction of the QS values to $\sim 0 \mathrm{~mm} / \mathrm{s}$, giving a clue that most of $\left[\mathrm{SnO}_{6}\right]$ units are likely transformed into regular octahedrons and that the structure symmetry could be improved with the oxygen vacancies significantly removed from the sample.

The local structural distortions of BS-T samples were further investigated using the Raman spectroscopy, and the results are shown in Figure 7. According to group theory, single-crystal

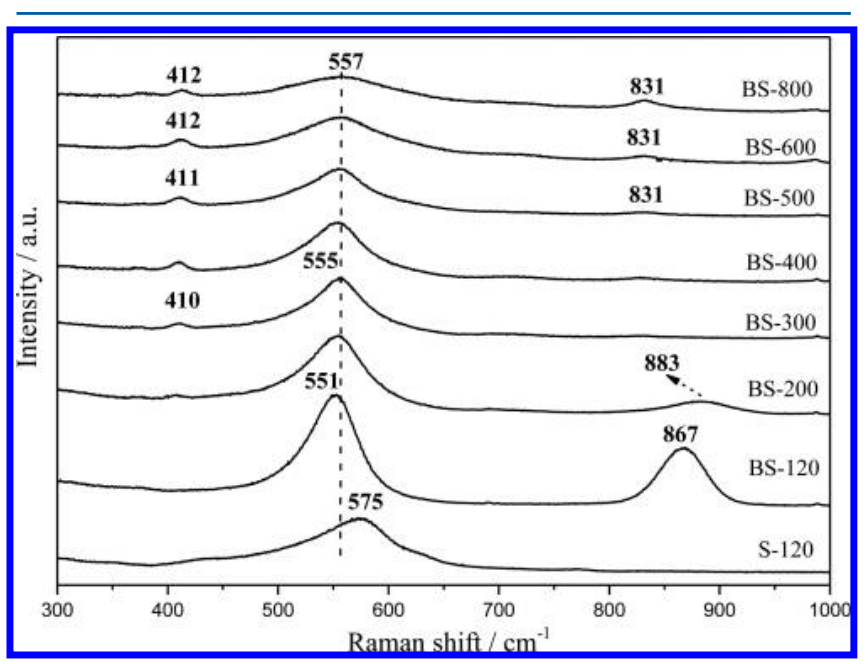

Figure 7. Raman spectrum of BS-T and S-120.

$\mathrm{BaSnO}_{3}$ with a centrosymmetric structure belonging to $\mathrm{Pm} 3 m$ space group can exhibit nonfirst-order Raman active modes. Therefore, the activation of phonons for BS-T may account for an ideal cubic structure with a lower internal symmetry. ${ }^{4,48}$ For BS-120, two Raman features can be observed at 551 and 867 $\mathrm{cm}^{-1}$, which could be assigned to the $\mathrm{Sn}-\mathrm{O}$ and $\mathrm{Sn}-\mathrm{O}-\mathrm{O}$ vibration modes, respectively. ${ }^{49}$ The peak corresponding to 
$\mathrm{Sn}-\mathrm{O}-\mathrm{O}$ vibration is significantly suppressed after calcination of the precursor at $200{ }^{\circ} \mathrm{C}$ because of the peroxo groups' decomposition. This result is in good agreement with the MS analysis (Figure $3 \mathrm{~b}$ ). The obvious blue shift of the peak for BS200 may be ascribed to the increase of $\mathrm{Sn}-\mathrm{O}-\mathrm{O}$ interaction, and this deduction is confirmed by the TPD experiment where the desorption peak of oxygen (Supporting Information, Figure S2) is shifted to higher temperature of $286^{\circ} \mathrm{C}$. After calcination at $300{ }^{\circ} \mathrm{C}$, the peak corresponding to the $\mathrm{Sn}-\mathrm{O}-\mathrm{O}$ vibration disappears, indicating that most of the peroxo groups have already vanished. Moreover, the stretching mode of $\mathrm{Sn}-\mathrm{O}$ bond around $549 \mathrm{~cm}^{-1}$ for BS-120 shifts to higher frequencies after calcination. This shift could be attributed to the strengthened $\mathrm{Sn}-\mathrm{O}$ interaction based on the Mössbauer analysis. Most importantly, the shift between BS-120 and BS200 is especially pronounced, which is consistent with the change of lattice parameters determined in the XRD patterns (Figure 2). It should be pointed out here that a similar Raman shift is also observed for $\mathrm{BiVO}_{4}$ materials. ${ }^{50,51}$ For BS-300 and BS-400, a new Raman band around $410 \mathrm{~cm}^{-1}$ emerges, which is likely induced by oxygen vacancies according to the reports by Balamurugan et $\mathrm{al}^{52}$ and Guo et $\mathrm{al}^{48}$ Another characteristic band located at $831 \mathrm{~cm}^{-1}$ is observed for BS-T samples calcined at 500,600 , and $800{ }^{\circ} \mathrm{C}$, while the intensity of vibrational bands decrease significantly for BS-600 and BS-800. This may be explained by the fact that the structure symmetry is improved as the surface area reduces and the oxygen vacancies decrease.

The existence of oxygen vacancies is further confirmed by measuring low-temperature heat capacities of BS-400, BS-500, BS-600, and BS-800 using a PPMS, and the experimental results are shown in Figure 8. According to the MS results

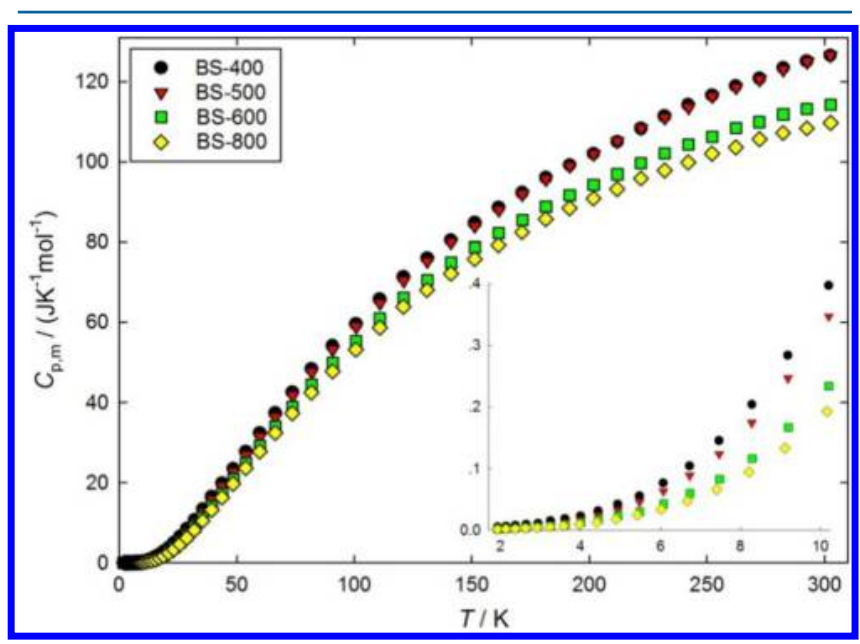

Figure 8. Plot of the experimental heat capacities of BS-T ( $T=400$, 500,600 , and 800) samples measured over the temperature range from 2 to $300 \mathrm{~K}$. (inset) The data below $10 \mathrm{~K}$.

(Figure 4b), the peroxo ligands have already been removed completely from these samples; therefore, the mass loss in the
TG experiment (Table 1) can be attributed to the water desorption. Consequently, the chemical formula of these BS-T samples used for molecular heat capacity calculation can be inscribed in the form of $\mathrm{BaSnO}_{3} \cdot n \mathrm{H}_{2} \mathrm{O}$, where the water content of $n$ can be determined to be $0.504,0.327,0.187$, and 0.017 for BS-400, BS-500, BS-600, and BS-800, respectively, based on the above TG measurements. ${ }^{53,54}$

The heat capacity of a substance at low temperature (normally below $25 \mathrm{~K}$ ) can be treated as a sum of contributions from electrons, lattice vibrations, nuclei, magnons, and impurities. ${ }^{55-57}$ Contributions of each property to the total heat capacity can be independently expressed using their corresponding theoretical functions. Therefore, some important information can be extracted by fitting the heat capacity data using these functions. For BS-T $(T=400,500,600$, and 800$)$ samples, the heat capacity data below $10 \mathrm{~K}$ was fitted using the following equation:

$$
c_{\mathrm{p}, \mathrm{m}}=\gamma T+B_{3} T^{3}+B_{5} T^{5}+B_{7} T^{7}
$$

where the $\gamma T$ is the contribution from the oxygen vacancies, and the rest represents the harmonic lattice model. ${ }^{55,58,59}$ The fitted parameters are listed in Table 3. Note that the contribution of the oxygen vacancies to the total heat capacity decreases with increasing calcination temperature, revealing that the vacancies are gradually removed during the calcination process. This conclusion agrees well with the results obtained in the Mössbauer spectra and Raman spectroscopy analysis. Additionally, the thermodynamic functions of these BS-T samples were also calculated based on the curve fitting of the experimental heat capacities, and the standard molar entropies of BS-400, BS-500, BS-600, and BS-800 at $298.15 \mathrm{~K}$ have been determined to be $141.69,139.78,129.09$, and $123.77 \mathrm{~J} \cdot \mathrm{K}^{-1}$. $\mathrm{mol}^{-1}$, respectively.

\section{CONCLUSIONS}

In the present work, we have developed a facile method for synthesizing large specific surface area mesoporous $\mathrm{BaSnO}_{3}$ by preparing a peroxo-precursor and calcining the precursor at relatively low temperatures. The specific surface area of the $\mathrm{BaSnO}_{3}$ obtained at the calcination temperature of $500{ }^{\circ} \mathrm{C}$ has been determined to be $67.2 \mathrm{~m}^{2} / \mathrm{g}$, which is the largest surface area reported in literature as far as we know, and the sample can be maintained at the relatively high surface area of ca. $30 \mathrm{~m}^{2} / \mathrm{g}$ even at calcination temperatures up to $800{ }^{\circ} \mathrm{C}$.

The structure evolution from the precursor to the $\mathrm{BaSnO}_{3}$ samples during the calcination process has been extensively investigated using a variety of characterization techniques. The results have suggested that the precursor possesses a significant amount of hydroxyl and peroxo groups, which leads to a large unit cell edge of $4.520 \AA$, weak $\mathrm{Sn}-\mathrm{O}$ interaction, and distorted $\left[\mathrm{SnO}_{6}\right]$ octahedral. After calcination at different temperatures, water and oxygen release during the calcination process and bring a mesoporous structure into the sample. Meanwhile, the lattice parameters decrease gradually, and $\mathrm{Sn}-\mathrm{O}$ interactions

Table 3. Fitted Parameters for BS-T $(T=400,500,600$, and 800) Samples

\begin{tabular}{ccrrr} 
parameter & \multicolumn{1}{c}{ BS-400 } & \multicolumn{1}{c}{ BS-500 } & \multicolumn{1}{c}{ BS-600 } & \multicolumn{1}{c}{ BS-800 } \\
$\gamma\left(\mathrm{J} \cdot \mathrm{K}^{-1} \cdot \mathrm{mol}^{-1}\right)$ & $2.05 \times 10^{-3}$ & $1.00 \times 10^{-3}$ & $4.69 \times 10^{-4}$ & $3.58 \times 10^{-4}$ \\
$\mathrm{~B}_{3}\left(\mathrm{~J} \cdot \mathrm{K}^{-1} \cdot \mathrm{mol}^{-1}\right)$ & $1.97 \times 10^{-4}$ & $1.76 \times 10^{-4}$ & $1.56 \times 10^{-4}$ & $1.21 \times 10^{-4}$ \\
$\mathrm{~B}_{5}\left(\mathrm{~J} \cdot \mathrm{K}^{-1} \cdot \mathrm{mol}^{-1}\right)$ & $2.83 \times 10^{-6}$ & $2.60 \times 10^{-6}$ & $6.40 \times 10^{-7}$ & $7.90 \times 10^{-7}$ \\
$\mathrm{~B}_{7}\left(\mathrm{~J} \cdot \mathrm{K}^{-1} \cdot \mathrm{mol}^{-1}\right)$ & $-1.29 \times 10^{-8}$ & $-1.23 \times 10^{-8}$ & $-4.40 \times 10^{-10}$ & $-2.05 \times 10^{-9}$
\end{tabular}


are strengthened. The symmetry of $\left[\mathrm{SnO}_{6}\right]$ octahedron is also improved during this process. However, oxygen vacancies are generated simultaneously, which contributes to the distortion of $\left[\mathrm{SnO}_{6}\right]$ octahedral as well.

The thermodynamic properties of $\mathrm{BaSnO}_{3}$ samples calcined above $400{ }^{\circ} \mathrm{C}$ were studied by PPMS. The results indicate a significant linear heat capacity contribution of the oxygen vacancies existing in the materials, and the concentration of the vacancies tends to decrease with the calcination temperature increasing. The standard molar entropies $(T=298.15 \mathrm{~K})$ of BS400 , BS-500, BS-600, and BS-800 are determined to be 141.69 , $139.78,129.09$, and $123.77 \mathrm{~J} \cdot \mathrm{K}^{-1} \cdot \mathrm{mol}^{-1}$, respectively, which are calculated based on the curve fitting of the experimental heat capacities.

\section{ASSOCIATED CONTENT}

\section{S Supporting Information}

Illustrations featuring additional $\mathrm{N}_{2}$ adsorption-desorption data and $\mathrm{O}_{2}$ TPD profile. This material is available free of charge via the Internet at http://pubs.acs.org.

\section{AUTHOR INFORMATION}

\section{Corresponding Authors}

*E-mail: xdwang@dicp.ac.cn. Phone: +86 411 84379680. Fax: +8641184379680 (X. W.).

*E-mail: shiquan@dicp.ac.cn. Phone: +86 41184379213 (Q. S.).

\section{Notes}

The authors declare no competing financial interest.

\section{ACKNOWLEDGMENTS}

Financial support from National Science Foundation of China (NSFC) Grants (21076211, 11205160, and 21473198) are greatly acknowledged.

\section{REFERENCES}

(1) Azad, A. M.; Hon, N. C. L. Alloys Compd. 1998, 270, 95-106.

(2) Mizoguchi, H.; Eng, H. W.; Woodward, P. M. Inorg. Chem. 2004, 43, 1667-1680.

(3) Mizoguchi, H.; Woodward, P. M.; Park, C. H.; Keszler, D. A. I. Am. Chem. Soc. 2004, 126, 9796-9800.

(4) Cerdà, J.; Arbiol, J.; Dezanneau, G.; Díaz, R.; Morante, J. R. Sens. Actuators, B 2002, 84, 21-25.

(5) Lampe, U.; Gerblinger, J.; Meixner, H. Sens. Actuators, B 1995, 25, $657-660$.

(6) Cerda, J.; Morante, J. R.; Spetz, A. L. $\mathrm{BaSnO}_{3}$ Oxygen Sensors without the Need of a Reference Electrode. Proceedings of the IEEE Sensors 2003, Vols 1 and 2; IEEE: New York, 2003; pp 1164-1165.

(7) Tao, S. W.; Gao, F.; Liu, X. Q.; Sorensen, O. T. Sens. Actuators, B 2000, 71, 223-227.

(8) Reddy, C. V. G.; Manorama, S. V.; Rao, V. J. L. Mater. Sci.: Mater. Electron. 2001, 12, 137-142.

(9) Hodjati, S.; Vaezzadeh, K.; Petit, C.; Pitchon, V.; Kiennemann, A. Appl. Catal., B 2000, 26, 5-16.

(10) Hodjati, S.; Vaezzadeh, K.; Petit, C.; Pitchon, V.; Kiennemann, A. Catal. Todav 2000, 59, 323-334.

(11) Kim, D. W.; Shin, S. S.; Lee, S.; Cho, I. S.; Kim, D. H.; Lee, C. W.; Jung, H. S.; Hong, K. S. ChemSusChem 2013, 6, 449-454.

(12) Shin, S. S.; Kim, J. S.; Suk, J. H.; Lee, K. D.; Kim, D. W.; Park, J. H.; Cho, I. S.; Hong, K. S.; Kim, J. Y. ACS Nano 2013, 7, 1027-1035. (13) Sallis, S.; Scanlon, D. O.; Chae, S. C.; Quackenbush, N. F.; Fischer, D. A.; Woicik, J. C.; Guo, J. H.; Cheong, S. W.; Piper, L. F. J. Appl. Phys. Lett. 2013, 103.
(14) Mizoguchi, H.; Chen, P.; Boolchand, P.; Ksenofontov, V.; Felser, C.; Barnes, P. W.; Woodward, P. M. Chem. Mater. 2013, 25, $3858-3866$.

(15) Liu, H.-R.; Yang, J.-H.; Xiang, H. J.; Gong, X. G.; Wei, S.-H. Appl. Phys. Lett. 2013, 102.

(16) Kim, H. J.; Kim, U.; Kim, T. H.; Kim, J.; Kim, H. M.; Jeon, B.G.; Lee, W.-J.; Mun, H. S.; Hong, K. T.; Yu, J.; Char, K.; Kim, K. H. Phvs. Rev. B: Condens. Matter 2012, 86, 165205.

(17) Scanlon, D. O. Phys. Rev. B: Condens. Matter 2013, 87.

(18) Hadjarab, B.; Trari, M.; Kebir, M. Mater. Sci. Semicond. Process. 2015, 29, 283-287.

(19) Li, G. J.; Kawi, S. Mater. Lett. 1998, 34, 99-102.

(20) Xu, C.; Tamaki, J.; Miura, N.; Yamazoe, N. Sens. Actuators, $B$ 1991, 3, 147-155.

(21) Tao, S.; Gao, F.; Liu, X.; Sørensen, O. T. Sens. Actuators, B 2000, $71,223-227$.

(22) Guo, F.-a.; Li, G.; Zhang, W. Int. J. Photoenergy 2010, 2010.

(23) Maekawa, T.; Kurosaki, K.; Yamanaka, S. L. Alloys Compd. 2006, 416, 214-217.

(24) Upadhyay, S.; Sahu, A. K.; Kumar, D.; Parkash, O. L. Appl. Phvs. 1998, 84, 828-832.

(25) Lu, W.; Schmidt, H. I. Eur. Ceram. Soc. 2005, 25, 919-925.

(26) Lu, W.; Schmidt, H. Ceram. Int. 2008, 34, 645-649.

(27) Song, Y. J.; Kim, S. I. Ind. Eng. Chem. 2001, 7, 183-185.

(28) Stanulis, A.; Sakirzanovas, S.; Van Bael, M.; Kareiva, A. I. SolGel Sci. Technol. 2012, 64, 643-652.

(29) Lu, W.; Schmidt, H. I. Sol-Gel Sci. Technol. 2007, 42, 55-64.

(30) Lu, W.; Schmidt, H. Adv. Powder Technol. 2008, 19, 1-12.

(31) Pfaff, G. I. Eur. Ceram. Soc. 1993, 12, 159-164.

(32) Sun, X.; Shi, Y.; Zhang, P.; Zheng, C.; Zheng, X.; Zhang, F.; Zhang, Y.; Guan, N.; Zhao, D.; Stucky, G. D. I. Am. Chem. Soc. 2011, $133,14542-14545$.

(33) Xiong, Z.; Dou, H.; Pan, J.; Ma, J.; Xu, C.; Zhao, X. $\underline{S}$. CrystEngComm 2010, 12, 3455-3457.

(34) Li, B.-h.; Tang, Y.-w.; Luo, L.-j.; Xiao, T.; Li, D.-w.; Hu, X.-y.; Yuan, M. Appl. Surf. Sci. 2010, 257, 197-202.

(35) Buscaglia, M. T.; Leoni, M.; Viviani, M.; Buscaglia, V.; Martinelli, A.; Testino, A.; Nanni, P. L. Mater. Res. 2003, 18, 560-566.

(36) Köferstein, R.; Abicht, H.-P.; Woltersdorf, J.; Pippel, E. Thermochim. Acta 2006, 441, 176-183.

(37) Rouquerol, J.; Avnir, D.; Fairbridge, C. W.; Everett, D. H.; Haynes, J. H.; Pernicone, N.; Ramsay, J. D. F.; Sing, K. S. W.; Unger, K. K. Pure Appl. Chem. 1994, 66, 1739-1758.

(38) Rouquerol, F.; Rouquerol, J.; Sing, K. Adsorption by Powders and Porous Solids; Academic Press: London, U.K., 1999.

(39) Stock, S.; Cullity, B. Elements of X-ray Diffraction; Prentice Hall: Upper Saddle River, NJ, 2001.

(40) Shi, Q.; Snow, C. L.; Boerio-Goates, J.; Woodfield, B. F. I. Chem. Thermodvn. 2010, 42, 1107-1115.

(41) Shi, Q.; Boerio-Goates, J.; Woodfield, B. F. I. Chem. Thermodvn. 2011, 43, 1263-1269.

(42) Epifani, M.; Alvisi, M.; Mirenghi, L.; Leo, G.; Siciliano, P.; Vasanelli, L. I. Am. Ceram. Soc. 2001, 84, 48-54.

(43) Sladkevich, S.; Gutkin, V.; Lev, O.; Legurova, E.; Khabibulin, D.; Fedotov, M.; Uvarov, V.; Tripol'skaya, T.; Prikhodchenko, P. I. SolGel Sci. Technol. 2009, 50, 229-240.

(44) Udawatte, C. P.; Kakihana, M.; Yoshimura, M. Solid State Ionics 1998, 108, 23-30.

(45) de Kergommeaux, A.; Faure-Vincent, J.; Pron, A.; de Bettignies, R.; Malaman, B.; Reiss, P. I. Am. Chem. Soc. 2012, 134, 11659-11666.

(46) Collins, G. S.; Kachnowski, T.; Benczer-Koller, N.; Pasternak, M. Phvs. Rev. B: Condens. Matter 1979, 19, 1369-1373.

(47) J. Clark, I.; Takeuchi, T.; Ohtori, N.; C. Sinclair, D. L. Mater. Chem. 1999, 9, 83-91.

(48) Guo, F.-a.; Li, G.; Yang, N.; Wang, W.; Zhang, W. Appl. Phvs. A: Mater. Sci. Process. 2012, 107, 813-817.

(49) Bajnoczi, E. G.; Czegledi, E.; Kuzmann, E.; Homonnay, Z.; Balint, S.; Dombi, G.; Forgo, P.; Berkesi, O.; Palinko, I.; Peintler, G.; Sipos, P.; Persson, I. Dalton Trans. 2014, 43, 17971-17979. 
(50) Gotić, M.; Musić, S.; Ivanda, M.; Šoufek, M.; Popović, S. J. Mol. Struct. 2005, 744-747, 535-540.

(51) Yu, J.; Kudo, A. Adv. Funct. Mater. 2006, 16, 2163-2169.

(52) Balamurugan, K.; Harish Kumar, N.; Ramachandran, B.; Ramachandra Rao, M. S.; Arout Chelvane, J.; Santhosh, P. N. Solid State Commun. 2009, 149, 884-887.

(53) Shi, Q.; Boerio-Goates, J.; Woodfield, K.; Rytting, M.; Pulsipher, K.; Spencer, E. C.; Ross, N. L.; Navrotsky, A.; Woodfield, B. F. I.Phvs. Chem. C 2012, 116, 3910-3917.

(54) Boerio-Goates, J.; Li, G.; Li, L.; Walker, T. F.; Parry, T.; Woodfield, B. F. Nano Lett. 2006, 6, 750-754.

(55) Shi, Q.; Park, T.-J.; Schliesser, J.; Navrotsky, A.; Woodfield, B. F. I. Chem. Thermodvn. 2014, 72, 77-84.

(56) Snow, C. L.; Shi, Q.; Boerio-Goates, J.; Woodfield, B. F. I. Chem. Thermodvn. 2010, 42, 1136-1141.

(57) Woodfield, B. F.; Wilson, M. L.; Byers, J. M. Phvs. Rev. Lett. 1997, 78, 3201-3204.

(58) Majzlan, J.; Navrotsky, A.; Woodfield, B. F.; Lang, B. E.; BoerioGoates, J.; Fisher, R. A. I. Low Temp. Phvs. 2003, 130, 69-76.

(59) Phillips, N. E. CRC Crit. Rev. Solid State Sci. 1971, 2, 467-553. 